\title{
Erratum to: Concerning Heritage: \\ Lessons from Rock Art Management in the Maloti-Drakensberg Park World Heritage Site
}

\author{
Ghilraen Laue, Sam Challis, and Alice Mullen
}

\section{Erratum to:}

Chapter 10 in: S. Makuvaza (ed.), Aspects of Management Planning for Cultural World Heritage Sites, https://doi.org/10.1007/978-3-319-69856-4_10

The original version of this chapter had only the first affiliation details updated for Dr. Ghilraen Laue. This has been corrected and the second affiliation details also has been updated as follows:

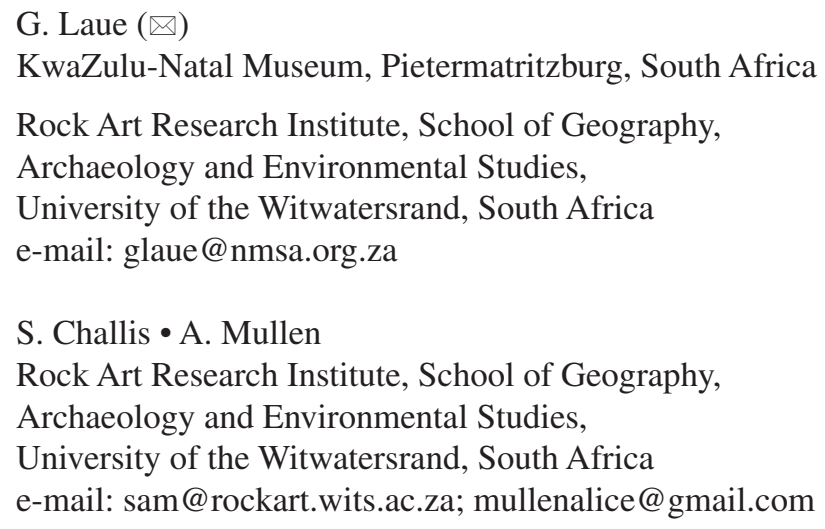

